\title{
THE COURSE WITHIN THE SPINAL CORD OF THE NON-MEDULLATED FIBERS OF THE DORSAL ROOTS: A STUDY OF LISSAUER'S TRACT IN THE CAT
}

\author{
S. WALTER RANSON
}

From the Anatomical Laboratory of the Northwestern University Medical School

ELEVEN FIGURES

It has been shown that the small nerve cells of the spinal ganglia give rise to non-medullated axons, each of which divides dichotomously into a small non-medullated fiber running toward the periphery and an even smaller one centrally directed in the dorsal root. These non-medullated fibers can be followed for long distances in the nerve on the one hand, and through the dorsal roots to the spinal cord on the other. Just as the small cells of the ganglion far outnumber the large cells, so the non-medullated fibers of the nerve and the dorsal root far outnumber those which are medullated. Since these facts with the related literature have recently been discussed in detail (Ranson '11, '12) it will be unnecessary to repeat them at length in this place.

Partly with reference to this problem and partly with reference to the variations in the pyramidal tracts, we have recently been studying the spinal cord in a number of mammals. In looking over the accumulated material it became evident that the sections of the spinal cord of the cat were especially suited for the solution of the problem of the central course of the afferent spinal non-medullated fibers. 'In fact, the course of these fibers stands out with diagrammatic clearness in the pyridine-silver preparations of the spinal cord of the cat. 


\section{TECHNIQUE}

The spinal cord of the cat forms very favorable material to which to apply the pyridine-silver technique. Preparations obtained from the cords of other laboratory animals (dogs, rabbits, guinea-pigs and rats) are not so perfect.

Under anaesthesia the animals were exsanguinated. The spinal cord was exposed and the ganglia on the $\mathrm{C}^{3}, \mathrm{C}^{7}, \mathrm{~T}^{4}, \mathrm{~T}^{8}, \mathrm{~T}^{12}, \mathrm{~L}^{5}$, and $\mathrm{S}^{1}$ spinal nerves were dissected out and left attached to their respective segments of the spinal cord. These segments with their associated roots and ganglia were then removed and freed from dura. Preparations were made by the Pal-Weigert as well as the pyridine-silver method. For the latter the pieces were not more than $5 \mathrm{~mm}$. long, and after the usual treatment (Ranson '11), were imbedded in paraffin and cut into sections varying from 8 to $12 \mu$ in thickness. Serial sections of a number of levels were mounted, to trace more in detail the entering bundles from the roots. The Pal-Weigert material was cut in celloidin into sections of $12 \mu$ and $24 \mu$ thickness. Usually sections of both thicknesses were cut from each segment. The technique of the silver stain has already been published (Ranson '11 and '12) and the Pal-Weigert method needs no explanation.

\section{Structure of the substantia alba of the spinal cord}

Cajal's silver method and its various modifications are known to give instructive preparations of the gray substance of the nervous system. In the preparations of the spinal cord of the cat it is superbly stained, showing the greatest detail in the pericellular fiber plexuses, and the endocellular fibrillar reticulum. It is, however, in the fiber columns of the cord that the pyridinesilver preparations present the most interesting differentiation. As in the peripheral nerves, the axons of the medullated fibers stain a light yellow and are surrounded by unstained rings of myelin; while the non-medullated axons are dark brown or black. Areas consisting chiefly of medullated fibers appear light yellow under low magnification because of the predominance of light yellow axons and unstained myelin. Other areas are lighter or 
darker brown according to the number of dark brown non-medullated axons which they contain. Under higher magnification the non-medullated axons are sharply differentiated from the faintly yellow, granular neuroglia. The neuroglia fibers are not differentiated.

We wish briefly to call attention to those tracts which immediately surround the posterior cornu.

The cuneate and gracile fasciculi are composed very largely of medullated fibers (fig. 1). But in the neighborhood of the posterior commissure and posterior cornu there are numerous nonmedullated fibers probably of endogenous origin. On the whole, however, these two fasciculi contain fewer non-medullated fibers than any other portion of the substantia alba, with one exception to be mentioned later. They are for this reason more lightly stained than is the anterior and most of the lateral funiculus. The number of non-medullated fibers in the fasciculus cuneatus and fasciculus gracilis is not sufficient to account for an upward continuation in these columns of the non-medullated fibers of the dorsal roots, and indicates that one must look elsewhere for their course within the cord.

The dorsal spino-cerebellar tract is also composed chiefly of medullated fibers, and is the most lightly stained of all the fiber columns of the cord. It is indicated in figure 1, $c$, as a light area contrasting sharply with the darker pyramidal tract $(d)$ and the still darker tract of Lissauer $(b)$. It is broadest near its posterior medial extremity where it is sharply marked off from the latter tract by a rather thick pial septum. It becomes gradually less distinct in an antero-lateral direction. Ventro-medially from this fasciculus and separated from it by no very sharp line is the pyramidal tract, $d$. The area occupied by the latter is somewhat rounded in outline and lies just lateral to the cervix and caput of the posterior cornu. Sharply outlined by its dark staining from the dorsal spino-cerebellar fasciculus, it is not so clearly separated from the remainder of the lateral funiculus. Next to Lissauer's tract the pyramidal tract is the darkest part of the substantia alba, and contains a very large number of non-medullated fibers. In comparison with the tract in the rat (Ranson '13), 
the cat's pyramidal tract is much better medullated and contains in addition to non-medullated and small medullated axons also large axons with thick myelin sheaths. This is not the place, however, to enter into a discussion of the comparative histology of the pyramidal tract.

\section{Lissauer's tract}

Pal-Weigert preparations. Lissauer's tract occupies the apex of the posterior cornu, lying just dorsal to the substantia gelatinosa. It occupies the entire apex, reaching to the surface of the cord, except in the thoracic segments. Here the substantia gelatinosa, capped by the tract of Lissauer is at some distance from the surface; and the posterior part of the apex consists of a thin pial septum. Because of the light stain which the tract takes in Weigert preparations it is usually considered as a part of the posterior cornu, although it is admitted by all that it properly belongs with the longitudinal fiber columns of the cord.

In Pal-Weigert preparations it is seen to consist of rather sparsely arranged and uniformly fine medullated fibers. The spacing is uniform, each fiber being separated from its neighbors by a considerable interval. There is no grouping of these fibers into bundles nor are there any large spaces devoid of fibers. The fibers for the most part run vertically in the bundle, but some have an inclination forward toward the substantia gelatinosa. The obliquity of the fibers is most pronounced at the posterior extremity of the tract and in the neighborhood of entering root bundles. Starting in the region of an entering root bundle and passing forward toward the substantia gelatinosa, one can often see all gradations between horizontal fibers, and oblique fibers and again between oblique and vertical fibers. This would be in harmony with the generally accepted view that the medullated fibers of this tract are derived from the dorsal root, a view which has recently been called into question. In addition to the vertical and oblique fibers, just mentioned, one sees horizontal fibers of fine caliber, a few in each section running long distances through the tract to enter the stubstantia gelatinosa. These are prob- 
ably in part fibers directly out of the dorsal roots which have not had a previous vertical course in the cord, and in part the horizontal continuation of the vertical fibers.

Although there is no septum separating the fasciculus cuneatus and entering root zone from Lissauer's tract, the border between the two is represented by a very sharp almost straight line; and the contrast between the closely packed large medullated fibers of the one and the more scattered fine medullated fibers of the other is very striking. On the lateral side the tract is separated from the lateral funiculus by a rather thick and very constant pial septum (not present in man). This pial septum never quite reaches the substantia gelatinosa; and ventral to this septum there is no sharp line of separation between this tract and the adjacent portion of the lateral funiculus. Lissauer's tract seems to extend laterally upon the dorsal surface of the substantia gelatinosa, its fine scattered medullated fibers gradually giving place to more thickly packed large ones.

This gradual transition between the ventral part of Lissauer's tract and the lateral funiculus attracted the attention vi Leszlényi ('12) who made a very elaborate comparative study of PalWeigert preparations of the spinal cord of mammals, birds and reptiles. He saw many oblique fibers in the transition zone between the tract of Lissauer and the lateral funiculus; and concluded that many of the vertical fibers of Lissauer's tract come from the lateral funiculus through this transition zone. But the evidence which he presents in his paper, and the observations which I have been able to make on the cord of the cat, do not seem to me to show anything more than that there is an intermingling of the fibers of Lissauer's tract with those of the lateral funiculus ventral to the pial septum.

Leszlényi states that in all the cords he examined, with the possible exception of the human cord, the dorsal root fibers enter the posterior funiculus in such' a way that one may be sure that no considerable number find their way into the tract of Lissauer. This seems to agree with the findings of Waldeyer ('88) on the cord of the gorilla, where few, if any, fibers could be traced from the dorsal roots into Lissauer's tract. Leszlényi finds, in all, four 
kinds of medullated fibers in the tract of Lissauer: (1) fibers from Flechsig's ground bundle; (2) fibers which unite the posterior and lateral funiculi at the same level; (3) fibers out of the substantia gelatinosa which after a short course enter the gray substance again, (4) in man and many animals there are horizontal fibers which come from the dorsal roots and cross the tract of Lissauer to enter the substantia gelatinosa. In his opinion the dorsal roots contribute practically nothing to the vertical fibers of the tract.

This seems to be borne out, in part at least, by experimental and pathological data. There are a large number of papers, dealing with the course of the dorsal root fibers within the spinal cord, based on a study of Marchi preparations of the cord after lesions of the dorsal roots. Human cords, in which extensive degeneration of the dorsal roots has resulted from tumors, syphilis and other causes, have been studied as well as the cords of animals in which the roots have been divided. Most of these papers, although describing extensive degeneration in the posterior funiculus, make no mention of any degeneration in the tract of Lissauer. (See the papers of Darkschewitsch '96, Frölich '04, Kopczynski '06, Marguliés '96, Orr '06, Wallenberg '98 and Zappert' '98.)

Nageotte ('03) states that the tract of Lissauer is composed of fine medullated fibers of endogenous origin. He maintains that they can not be derived from the dorsal roots, because in a case reported by him, in which a tumor involved all the spinal roots in the cauda equina up to and including the fourth lumbar, the fine fibers of the tract of Lissauer were intact. The presence of these intact fibers in this case shows conclusively that many, perhaps a majority, of the fine vertical medullated fibers of this tract are of endogenous origin. It can not be taken as conclusive proof that none of the fibers in this tract are derived from the dorsal roots.

Laignel-Lavastine ('08) studied the spinal cord in a case of syphilis involving the cauda equina. The Marchi stain showed a very few degenerating fibers in Lissauer's tract, and the Weigert stain showed the vast majority of the fibers in this tract to be 
intact. He admits the contention of Nageotte that such degeneration as he finds may be tertiary, but insists that one cannot be certain that the tract does not contain some fibers from the posterior roots.

Sibelius ('05), who studied three cases in which the cauda equina was involved, found some degeneration in Lissauer's tract which he considers as the direct result of the root lesion. $\mathrm{He}$ explains the negative findings of Nageotte by assuming that the fine horizontal fibers of Lissauer's tractt had disappeared and that the author had failed to notice their absence. This explanation is tantamount to an admission that the proportion of dorsal root fibers in the tract is small and that they are chiefly horizontal.

Sottas ('93) and Collier and Buzzard ('03) find a limited amount of degeneration in Lissauer's tract after dorsal root lesion

The evidence seems to show that the medullated fibers in the tract of Lissauer are in part endogenous and in part exogenous and that the endogenous fibers predominate. We shall return to this question again in discussing the entrance of the dorsal root fibers into the spinal cord.

Pyridine-silver preparations. In pyridine-silver preparations the tract of Lissauer is stained very dark and is even more sharply outlined from the rest of the cord than in the Pal-Weigert preparations. It is seen to consist of vertically or obliquely coursing axons of the smallest diameter (fig. 2,b). These are stained a brownish black and are very sharply differentiated from the almost colorless background. They are very closely set together, although there are scattered among them a few medium sized yellowish brown axons which correspond in number and arrangement to the medullated fibers seen in the Pal-Weigert preparations. When compared with Pal-Weigert preparations of the same segment of the cord the contrast is very striking. In the latter the tract of Lissauer is very lightly stained and is seen to consist of rather sparsely scattered fine medullated fibers. A glance at the two preparations is sufficient to show that the number of axons in the one is several times greater than the number of myelin sheaths in the other. Lissauer's tract consists then in part of small medullated fibers but its chief and charac- 
teristic content is an enormous number of fine vertically coursing non-medullated fibers:

Before taking up the account of the course taken by the dorsal root fibers as they enter the cord it will be desirable to call attention to the variations in shape and topography of the tract of Lissauer at different levels in the cat's cord. In the cervical region as illustrated by the seventh cervical segment (fig. 1) the tract is long and narrow, since the substantia gelatinosa is at some distance from the surface of the cord and the tract fills the entire apex of the posterior cornu. Throughout the entire thoracic region of the cord (fig. 3, T. 8) the posterior cornu is not well developed; the substantia gelatinosa is placed a long distance from the surface of the cord; and the cone-shaped Lissauer's tract which caps it is also some distance removed from the surface. The apex of the cone is connected with the surface by a septum containing few fibers; occasionally isolated portions of Lissauer's tract are seen along the medial side of this septum. In the lumbar cord (fig. 4, L. 5) the substantia gelatinosa has approached the surface; and the tract of Lissauer, which fills the interval between it and the surface has become short and wide. In the sacral region (fig. 5, S. 1) the substantia gelatinosa has flattened out laterally and the tract of Lissauer occupies a short but wide interval between it and the periphery of the cord.

The size of the tract varies somewhat from level to level and seems to be roughly in proportion to the size of the nerve roots entering at that and adjacent levels. The first sacral segment seems to be an exception to this rule. Although its entering rootlets are larger, it presents a Lissauer's tract somewhat smaller than that in the fifth lumbar segment. These facts would be easily explained if we assume that the majority of the non-medullated fibers in the tract are short ascending fibers from the dorsal roots. The small rootlets of the lower sacral segments would then contribute fewer ascending fibers to the tract in the first sacral segment, than would be contributed by the large rootlets of the upper sacral and last two lumbar nerves to the tract in the fifth lumbar segment. The ascending fibers must be relatively short, however. Otherwise there would be a steady increase 
in size from lower to high levels in the cord. But the tract seems rather to be proportional in size to the entering rootlets; and instead of a steady increase in size in an ascending direction, there is a marked decrease in going from the lower lumbar into the thoracic cord and again in passing from the lower cervical to the upper cervical segments. These facts indicate that the majority of the non-medullated fibers are short ascending fibers and in the next section we will show that many, probably a great majority, are derived from the dorsal roots.

\section{Entrance of the dorsal roots into the spinal cord}

Pal-Weigert preparations. In 1885 Lissauer observed tlat fine medullated fibers grouped themselves on the lateral side of an entering rootlet and turning lateralward separated themselves from the remainder of the rootlet to enter the apex of the posterior horn, where they turned to run vertically in the tract which now bears his name. Similar observations were made by Bechterew ('86), and have formed the basis of the standard text-book accounts of this tract. It is an easy matter to confirm these observations in Pal-Weigert preparations of the cat's cord, especially in the case of the larger cervical and sacral roots. There can be no doubt that in the cat medullated fibers enter the tract of Lissauer from the dorsal roots in considerable number, and in exactly the manner described by Lissauer and Bechterew. There can also he no doubt, on the basis of the pathological and experimental evidence presented in preceding paragraphs, that these medullated fibers from the dorsal root do not constitute all or even the majority of the medullated fibers in this tract.

Pyridine-silver preparations. To the medial side of the tract of Lissauer is the entering root zone. In this region the medullated fibers, which have just entered the cord, can be seen running more or less obliquely (fig. 10,a). The fibers seen here are for the most part large medullated ones; and, when one remembers the large number of non-medullated fibers seen in the dorsal root, one is impressed with the scarcity of these fibers in the entering root zone. Somewhat further medialward large numbers of fine 
collaterals are given off from the medullated fibers and take a more or less oblique course toward the posterior horn. But these, for the most part, take a much lighter stain than the non-medullated fibers. Occasionally medium sized bundles of non-medullated fibers are seen in the entering root zone as at $e$ in figure 10, but such bundles usually have a direction nearly at right angles to the medullated fibers, and are making their way toward the tract of Lissauer. We shall see that the majority of non-medullated fibers separate themselves from the medullated just before the entrance into the cord. The scattered non-medullated fibers as well as the bundles of such fibers in the entering root zone, were delayed in their separation from the medullated fibers; but most of them finally find their way into the tract of Lissauer. It is possible, however, that a few of the non-medullated fibers pass medially to the tract of Lissauer and enter the fasciculus cuneatus.

A dorsal root as it enters the cord is broken up into a large number of fila radicularia or rootlets. As each rootlet enters the cord it is surrounded and constricted by an encircling band of pia. Shortly before the rootlet reaches this constricting band, the non-medullated fibers, which nearer the ganglion have been distributed quite uniformly throughout the root, separate out from the medullated ones and come to lie either at the periphery of the radicles or along septa which divide the radicles into smaller bundles. In this way large flat bundles of non-medullated fibers are formed; often a thin layer of such fibers is seen making a complete tubular sheath at the periphery of the radicle In serial sections it is possible to trace these compact bundles into the cord and see that they enter Lissauer's tract. It is this early separation of these fibers from the main mass of the radicle that causes the entering root zone to be composed almost entirely of medullated fibers.

We will now take several typical instances and show how these fibers can be traced into Lissauer's tract. In the first sacral segment (figs. 5, 6 and 7) the radicles are of good size and are divided by connective tissue septa, running in a general anteroposterior direction, into smaller fascicles which are displaced 
medially as one after another enters the cord. Figure 5 is a diagrammatic representation of the level from which figures 6 and 7 were taken. At $a$ is indicated the tract of Lissauer; $b$ and $c$ represent connective tissue septa. In the high power drawings the same lettering has been used. In figure 6 one sees that most of the non-medullated fibers have separated out from among the medullated and arranged themselves along the septa $b$ and $c$. At $d$ and $d$ are seen bundles of non-medullated fibers arranged along the inner border and the medial part of the posterior border of the radicle. The fibers in bundle $d$ can be traced at this level into Lissauer's tract. The fibers in $d^{\prime}$ can be traced along the surface of the cord for a short distance and then turn ventrally into the same tract. Bundle $c$ is composed of fibers which have separated out from the two root fascicles between which it lies. It is composed of two layers of fibers arranged one on each side of a connective tissue septum. If one follow this bundle upward in the serial sections its fibers are seen to turn ventrally and run into the tract of Lissauer (fig. 7, c). These fibers along the connective tissue septa of the roots are in size and staining reaction exactly like the non-medullated fibers which farther distally are scattered uniformly through the roots. They are also identical in size and staining reaction with the non-medullated fibers of the tract of Lissauer into which they have just been followed. It seems that a clearer demonstration of the fate of the nonmedullated fibers of the dorsal roots could scarcely be desired.

In the fifth lumbar segment of the cat's cord the entering radicles are smaller. Only when they are covered by a thick coat of connective tissue and bound down tightly to the surface of the cord are the physical conditions satisfactory for the impregnation of the non-medullated fibers. Figures 4 and 8 show such a rootlet entering the cord. Notice that its fibers pass through Lissauer's tract and separate off a small dorso-median portion from the main tract. This unites again with the rest of the tract above and below the entering root bundle. The constricting ring at the entrance of a radicle into the cord is well seen in figure 8. Points $a$ and $c$ are joined in the thickness of this section and the next by an arched band of connective tissue. The 
projecting points and this band form part of the constricting ring. Upon the surface of this band and separating it from the medullated fibers of the bundle can be seen a layer of closely packed non-medullated fibers, $b$. They can be followed for only a short distance at $b$ as they arch over the constricting band but between $b$ and $c$ they can be traced over this band into Lissauer's tract. Along the ventral surface $(d)$ of the extra-medullary part of the bundle and along the connective tissue septum (e) separating this from the next root bundle the non-medullated fibers have accumulated. Along the line $a, b, c, d, e$, there is indicated a peripheral layer of non-medullated fibers which a little more than half surrounds the bundle of entering medullated fibers. Whether a similar layer is present on the dorso-medial surface of the radicle it is impossible to say, since it is not likely that the fibers would take the stain in this superficial position if they were present.

The general principles which govern the entrance of the nonmedullated fibers into the cord are well illustrated by the radicle from the seventh cervical dorsal root which is shown at three levels in figures 9,10 and 11 . The lettering in these three figures is the same as in figure 1 from the same segment and to which reference should be made for orientation. Figure 9 is from a section just above the level of entrance of the radicle in question. The medullated fibers of this rootlet are seen cut obliquely at $a$, and at $b$ is indicated the tract of Lissauer. At 1 is seen a bundle of non-medullated fibers which are arching ventro-laterally over the obliquely coursing medullated fibers, $a$, of the entering rootlet. Dorso-laterally bundle 1 is continuous with bundle 2 of more vertically running fibers. A study of serial sections shows that bundle 1 is derived from two sources. First there are upon the upper surface of bundle $a$, as it enters the cord, a large number of non-medullated fibers which turn upward and then ventro-laterally to enter into the formation of bundle 1. A few of the uppermost of these are seen at 3 . The second group of fibers entering into bundle 1 are derived from bundle 2 .

Tracing the same structures downward through the series we find them arranged as in figure 10. Here bundle $a$, composed 
chiefly of medullated fibers, is seen entering the cord. At 4 a bundle of non-medullated fibers can be seen running over the constricting ring to pass directly into the tract of Lissauer on entering the cord. At 5 are seen a few non-medullated fibers gathering along a line which represents the beginning of a line of separation between two fascicles of the root. Bundle 2 is larger here than in the preceding section and is placed between bundle $a$ and another bundle more dorsally situated. It is composed of fibers which have separated out from these two bundles and especially from bundle $a$, and, instead of running directly across the bundle of medullated fibers to reach Lissauer's tract, have turned upward or downward on the dorsal surface of bundle $a$. In this way a vertical bundle of large size is formed, which traced upward is seen to arch ventro-laterally over the upper surface of bundle $a$ to form part of bundle 1 , figure 9 , and so to reach the tract of Lissauer. Traced downward, the descending fibers which enter into its composition are seen to turn ventro-laterally below bundle $a$ to run into Lissauer's tract (fig. 11). Here they form part of a. rather wide band of fibers on the medial and under surface of bundle $a$. A part of this band is seen at 6 , figure 11 . But the band is much wider than is indicated in the figure. In the succeeding sections the band is seen to underlie bundle $a$ to the very edge of the cord. This band is composed in part of fibers derived from bundle 2, figure 10, and in part from fibers entering the cord as a layer upon the under surface of bundle. $a$.

It thus appears that the non-medullated fibers separate out from the bundles of entering root fibers. They occupy the periphery of the bundles as these enter the cord and then take the route of least resistance to reach Lissauer's tract. In the case of the fibers on the dorso-medial surface of such entering root bundles this path of least resistance is usually around the bundle of entering medullated fibers rather than through it. For this reason these fibers form bundles arching over or under the bundle of medullated fibers. For those non-medullated fibers occupying the ventro-lateral portion of the surface of the entering dorsal root bundle the path to Lissauer's tract is direct (fig. 10,4). In 
the case of the first sacral segment the non-medullated fibers separate out along the septa separating the fascicles of the rootlet, and run forward along these septa into the underlying Lissauer's tract before the rest of the bundle has entered the cord.

The non-medullated fibers of the dorsal root, then, enter the tract of Lissauer, of which they form the chief and characteristic part. They run for short distances in this tract chiefly in an ascending direction and then probably pass forward into the substantia gelatinosa. The close relation of Lissauer's tract to this peculiar substance which caps the posterior horn, the fact that fibers can be seen passing from one into the other, and the fact that there is no other apparent outlet for the fibers of Lissauer's tract indicate that the substantia gelatinosa is the probable nucleus of reception of these non-medullated fibers. The fact that the substantia gelatinosa contains a large number of very small nerve cells and many non-medullated nerve fibers is of interest in connection with the probable relation of the two structures. Experimental evidence is needed, however, to prove this relation conclusively.

So far as the function of the non-medullated fibers is concerned, their course within the cord shows that they can have little or nothing to do with the afferent impulses received from muscles and joints which travel up the posterior funiculus. This does not necessarily include muscle and joint pain. Their early termination within the gray substance would agree with the course of the sensations of pain and temperature and probably also with that of touch. But there are, of course, no data on which one would care to hazard a guess as to their function, beyond the statement that they can have little or nothing to do with those sensations which are known to travel directly upward in the posterior funiculus. 


\section{SUMMARY}

1. The small cells of the spinal ganglion give rise to nonmedullated fibers whose centrally directed branches form the nonmedullated fibers of the dorsal roots.

2. The non-medullated fibers of the dorsal roots can be traced with diagrammatic clearness into Lissauer's tract.

3. The tract of Lissauer contains rather sparsely arranged fine medullated fibers which are in part derived from the dorsal roots but are in greater part of endogenous origin.

4. The tract of Lissauer contains a very great number of fine non-medullated axons, at least the great majority of which are derived from the non-medullated fibers of the dorsal roots.

5 . It is probable that the substantia gelatinosa is the nucleus of reception for the non-medullated fibers.

6. It seems clear that the non-medullated fibers have little or nothing to do with the transmission of the afferent impulses from the muscles and joints, at least with such part of these impulses as are transmitted upward in the posterior funiculi.

\section{BIBLIOGRAPHY}

BechтрRew, W. 1886 Über einen besonderen Bestandtheil der Seitenstränge des Rückenmarks und über den Faserursprung der grossen aufsteigenden Trigeminuswurzel. Arch. f. Anat. u. Physiol., Anat. Abt., p. 1.

Collier, Jamps, and Buzzard, E. F. 1903 The degenerations resulting from lesions of posterior nerve roots and from transverse lesions of the spinal cord in man. Brain, vol. 26, p. 559.

Darkschewitsch, L. O. 1896 Zur Frage von den secondären Veränderungen der weissen Substanz des Rückenmarks bei Erkrankung der Cauda equina. Neurol. Centralbl., vol. 15, p. 5.

Frölıch, A. 1904 Beitrag zur Kenntniss des intraspinalen Faserverlaufes einzelner hinterer Rückenmarkswurzeln. Arb. a. d. Neur. Inst., Wien., Bd. 11, p. 378.

GoldsteIN, K. 1903 Die Zusammensetzung der Rückenmarkshinterstränge. Monatschr. f. Psych. u. Neur., Bd. 14, p. 401.

JАсовsонN, L. 1907 Beiträge zum intramedullären Verlaufe von hinteren Wurzeln des Cornus medullaris. Neurol. Centralbl., Bd. 26, p. 386.

Kopcrznski, S. 1906 Experimentelle Untersuchungen aus dem Gebiete der Anatomie und Physiologie der hinteren Spinalwurzeln. Neurol. Centralbl., Bd. 25, p. 297.

Laignel-Lavastine 1908 Le système des fibres endogènes des cordons postérieurs dans la dégénérescence ascendante des racines de la queue de cheval. Compt. rend. Soc. de biol. T. 64, p. 223. 
LeszLênNI, O. 1912 Vergleichend-anatomische Studie über die Lissauersche Randzone des Hinterhorns. Arbeiten a. d. Neurologischen Inst., Wien, Bd. 19 , p. 252.

Lissader, H. 1885 Beitrag zur pathologischen Anatomie der Tabes dorsalis und zum Faserverlauf in menschlichen Rückenmark. Neurol. Centralbl., Bd. 4, p. 245.

Margultes, A. 1896 Zur Lehre vom Verlaufe der hinteren Wurzeln beim Menschen. Neurol Centralbl., Bd. 15, p. 347.

NAGeotre, M. J. 1903 Note sur les fibres endogènes grosses et fines des cordons postérieurs et sur la nature endogène des zones de Lissauer. Compt. rend. Soc. biol. T. 55, p. 1651.

ORR, D. 1906 The descending degenerations of the posterior columns in transverse myelitis and after compression of the dorsal posterior roots by tumors. Rev. of Neurol., and Psychiat., vol. 4, p. 488.

Ranson, S. W. 1911 Non-medullated nerve fibers in the spinal nerves. Am. Jour. Anat., vol. 12, p. 67.

1912 The structure of the spinal ganglia and of the spinal nerves. Jour. Comp. Neur., vol. 22, p. 159.

1913 The fasciculus cerebro-spinalis in the albino rat. Am. Jour. Anat., vol. 14, p. 411.

Sibelius, C. 1905 Drei Fälle von Caudaaffektionen nebst Beiträgen zur topographischen Analyse der Hinterstrangserkrankungen. Arbeiten a. d. Path. Inst. Univ. Helsingfors., Bd., 1, p. 79

Sottas, J. 1893 Des Dégénérescences de la Moelle Consécutives aux Lésions des Racines Postérieures. Rev. de Médicine, T. 13, p. 290.

Waldeyer, W. 1888 Das Gorillarückenmark. Abhandlungen -der Berliner Akademie; cited after Leszlényi.

Wallenberg, A. 1898 Beiträge Topographie der Hinterstrange des Menschen. Deut. Zeitschr. f. Nervenheil., Bd. 13, p. 441.

ZAPPERT, J. 1898 Beiträge zur absteigenden Hinterstrangsdegeneration. Neurol. Centralbl., Bd. 17, p. 102.

\section{PLATE 1}

EXPLANATION OF FIGURE

The drawings were made with the aid of a camera lucida from pyridine-silver preparations of the spinal cord of the cat.

1 From the seventh cervical segment. The substantia grisea presents a dense mass of interlacing fibers. The nerve cells are indicated in solid black. Capping the posterior cornu is the lightly staining substantia gelatinosa. More dorsally is seen the darkly staining tract of Lissauer, $b$. At $a$, is seen the obliquely cut medullated fibers of the entering dorsal root in the fasciculus cuneatus. At $c$, is represented the dorsal spino-cerebellar tract, and at $d$, the pyramidal tract. The differentiation of the fiber columns of the cord shown in the drawing is due to the varying proportion of non-medullated fibers which they contain. These are most abundant in the tract of Lissauer. The pyramidal tract contains the next greatest number, and the dorsal spino-cerebellar tract the fewest. $\times 23$. 


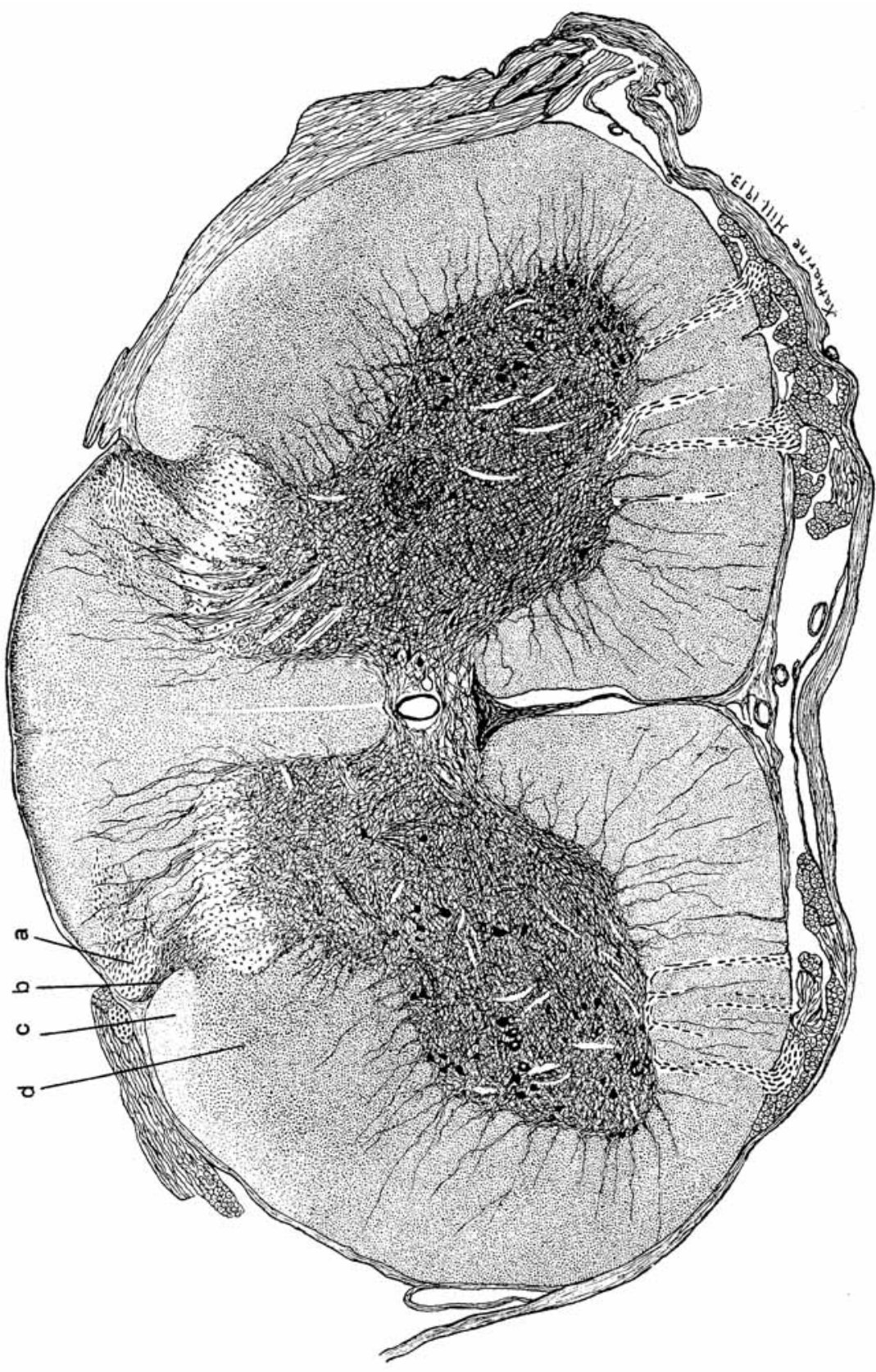

275

THE JOURNAT, OF COMPARATIVE NEUROLOGY, VOL. 23, NO. 4 
PLATE 2

EXPLANATION OF FIGURES

2 From the seventh cervical segment. A narrow strip at right angles to the apex of the posterior cornu: $a$, fasciculus cuneatus; $b$, Lissauer's tract; $c$, the dor sal spino-cerebellar tract. The medium sized and large lightly stained axons are medullated, the fine darkly stained ones non-medullated. The latter are very numerous and closely packed together in the tract of Lissauer. $\quad \times 648$.

3 Diagrammatic representation of the eighth thoracic segment, showing the shape and position of Lissauer's tract. $\times 17$.

4 Diagrammatic representation of the fifth lumbar segment, showing the shape and position of Lissauer's tract. $\times 17$.

5 Diagrammatic representation of the first sacral segment, showing the shape and position of Lissauer's tract. $a$, Lissauer's tract, $b$ and $c$, connective tissue septa dividing the entering root bundle into smaller fascicles. Bundles of nonmedullated fibers are grouped along these septa. Other bundles of non-medullated fibers are seen at $d$ and $d^{\prime} . \times 17$. 
S. WALTER RANGON
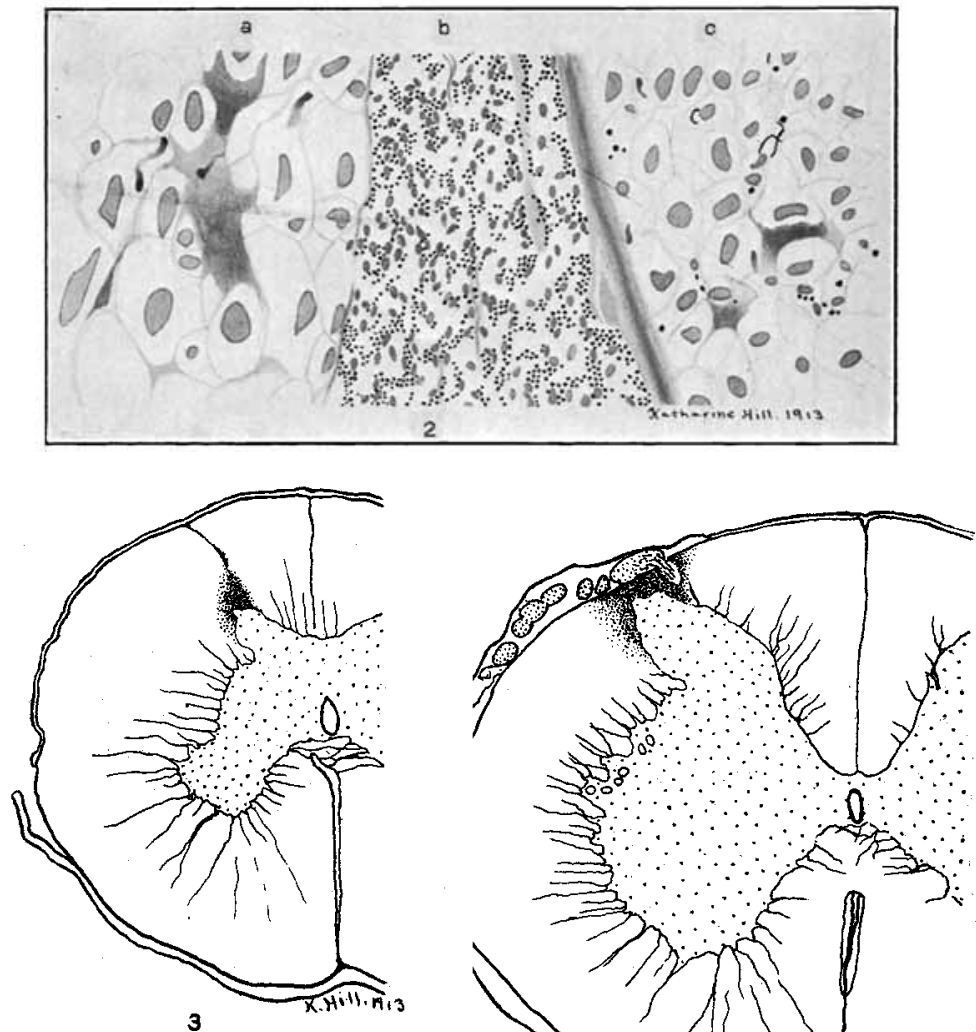

3
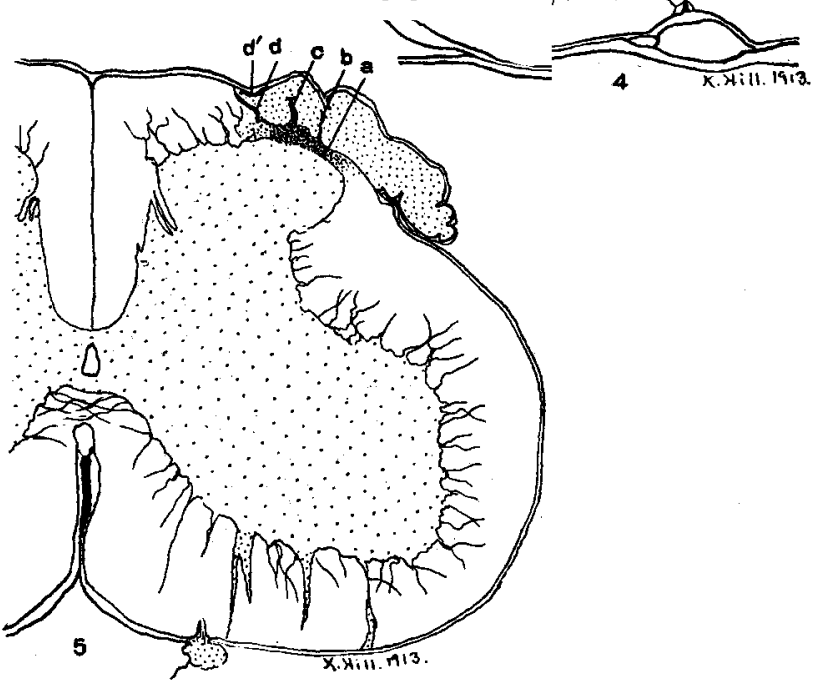
PLATE 3

EXPLANATION OF FIGURES

6 Lissauer's tract and entering dorsal root in the first sacral segment. Lettering is the same as in figure 5, which gives the topography of the high power drawing. Non-medullated fibers are separating out along the borders of the entering radicle and along the connective tissue septa which separate it into fascicles. At $d$ nonmedullated fibers are seen running forward into Lissauer's tract. $\times 100$.

7 Same area as represented in figure 6 but about $50 \mu$ farther cephalad. Lettering the same as in figures 5 and 6 . The non-medullated fibers of the dorsal root, which have separated out along the connective tissue septum $c$, are seen running forward into the tract of Lissauer, $a . \quad \times 100$.

8 Lissauer's tract and entering dorsal root in the fifth lumbar segment. For topography see figure 4. At $a, b, c$, is seen a part of an encircling band of pia which surrounds and constricts the entering radicle. Upon the surface of this band a layer of non-medullated fibers is seen entering the cord. At $d$, and $e$, are seen thin layers of non-medullated fibers at the periphery of the radicle and along the septum separating the radicle into two fascicles. $\times 100$. 

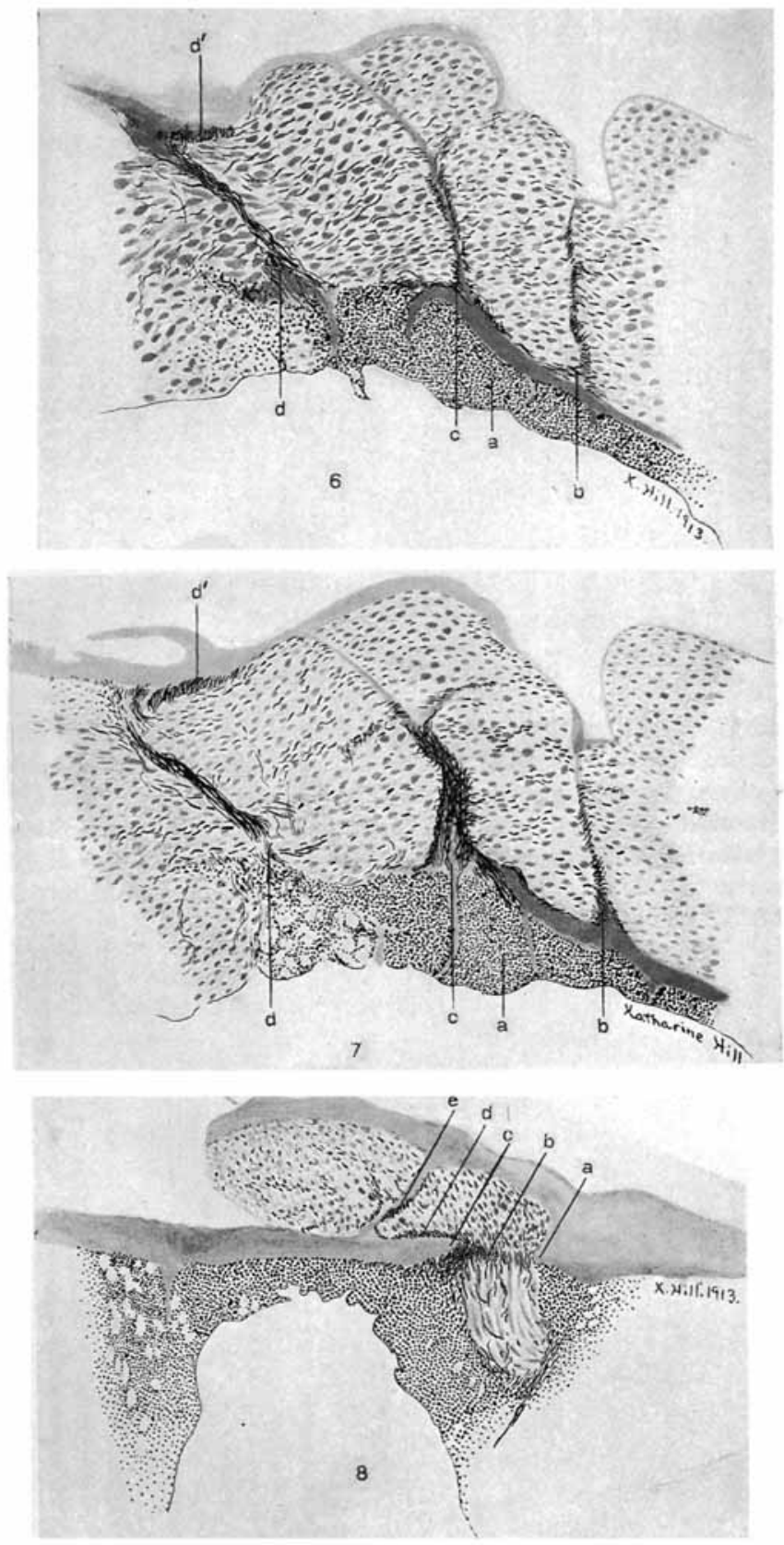


\section{PLATE 4}

\section{EXPLANATION OF FIGURES}

9, 10 and 11 Three sections from a series through an entering radicle of the seventh cervical dorsal root. For topography see figure 1. Figure 9 represents a level just above the entrance of the radicle $(a)$ into the cord, figure 10, a level through the middle of the entering radicle, and figure 11 , a level near its lower margin. The lettering is the same as that in figure 1 . At $1,2,3,4,5$ and 6 are indicated bundles of non-medullated fibers which can all be traced into Lissauer's tract. $\times 82$. 
LISSAUER'S TRACT IN THE CAT

s. WALTER RANSON

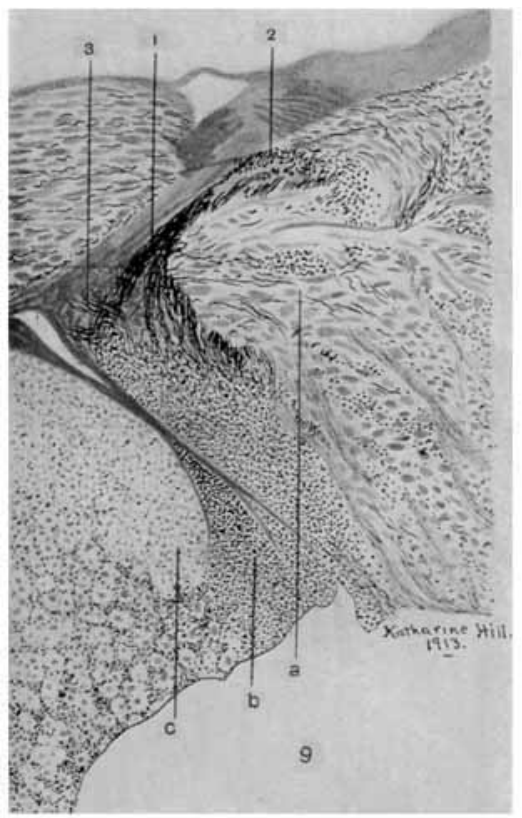

PLATE 4

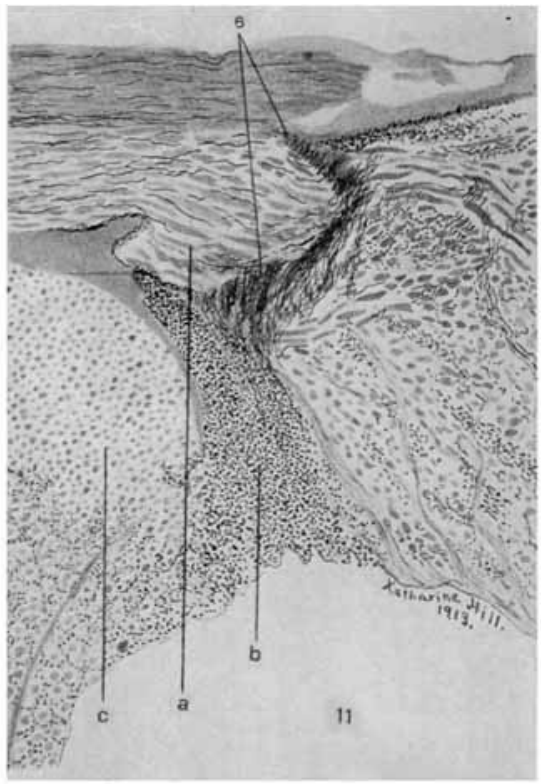

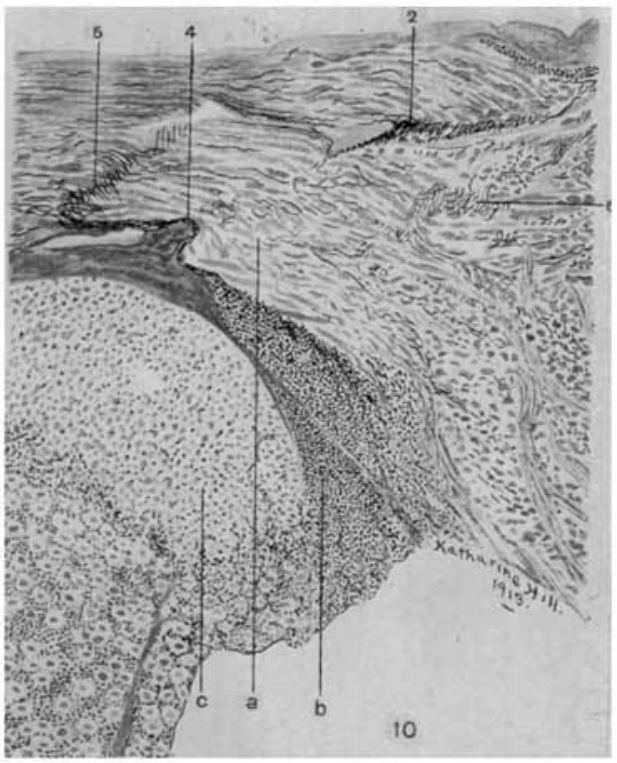

281 